\title{
Contemporary Paradigm of Development Communication: Gaps \& Dogma Between 2008 - 2018
}

\author{
Ashiru Kabir Matazu ${ }^{1}$ Beryl Ehondor ${ }^{2 *}$ \\ School of Media \& Communication, Pan-Atlantic University, Lagos, Nigeria \\ * E-mail of the corresponding author: beryl.ehondor@pau.edu.ng
}

\begin{abstract}
Development is a product of collaboration and participation of all stakeholders, and communication is seen as an essential tool for participation. Development communication is critical to national development, and citizens are at the centre of this. The advent of new media technologies amplified the potential for participation in the public sphere. Consequently, discerning democratic governments appreciate the need for active discourse among citizens so that their needs can truly be understood and met. Thus, this study assessed the development communicativity to citizens of a democratic government in West Africa over ten years, 2008-2018. Findings indicated a preponderance of old media channels used by the government, huge gaps in development and communication to citizens. It also found a nexus of communication preferences and opportunity for optimised development communication to foster national development. This study is strategic as it aligns with the United Nations democracy plan and vision which encompasses civilisation, governance and developmental democracy. This paper's significance is the intricate detail of how a specific nation is faring, developments occurring, the societal impact and communication expectations from a citizen purview. Theories engaged are the Paradigm of modernisation, dependency and the Paradigm of Another Development/Multiplicity.
\end{abstract}

Keywords: Development Communication, Nigeria, Paradigm of Multiplicity, Democracy

DOI: $10.7176 / \mathrm{DCS} / 11-5-06$

Publication date:May $31^{\text {st }} 2021$

\section{Introduction}

Before developing new media, the public sphere was primarily limited in its workings, mainly in the European coffee shops. Old media allowed for singular narratives and discussions held in different society portions by the same people. Hence, it wasn't easy to influence the political ecosystem of other people. With the advent of new media technologies, the potentials for participation in the public sphere have skyrocketed. Consequently, democratic governments of different countries now understand that there is a need for active discourse among citizens so that their needs can truly be understood. This study thus assessed the development communicativity of a democratic government in West Africa over ten years. This study is strategic as it aligns with the United Nations democracy plan and vision which encompasses civilisation, governance and developmental democracy. This paper's significance is the intricate detail of how a specific nation is faring, developments occurring, the societal impact and communication expectations from a citizen purview.

Development communication is very economically significant as its entirety aims to bring sustainable development through disseminating information. However, some of the discourses around this are often centred around which approaches should be taken to gathering information and then communicating it to members of the society. This arises from the fact that humans are considered significant development influencers, as they are the ones who really can tell rulers and decision-makers in the society what their needs are and, to an extent, inform how these needs should be met. This paper presents a discourse on perspectives of development communications by scholars, especially from a development standpoint. It also examines the different paradigms of development communication and an approach-based viewpoint of the concept. The paper also assesses development communication over a decade in Nigeria and makes recommendations that significantly adapt the new media to national discourse towards sustainable growth and economic development.

The paper further discusses the different views held on the concept of new media and the public sphere and see how these two concepts within the context of development communication impact a national space. The discourse answers some critical issues such as development communication concepts, the pragmatic place of new media vis-à-vis traditional forms of the media for national communication. The study presents an assessment of communicativity channels on a national scale over ten years based on findings. It proposes a contemporary paradigm based on conclusions for contextual public sphere discourse on national development 
communication. This paper ventures into addressing the issues above via survey and interpretive analysis. The survey draws data covering development communication from the government to the citizenry over a ten-year duration, i.e. 2008-2018.

\section{Conceptual Framework Development Communication}

Development communication enables society members to be informed (and provide information) that will make their lives better. Communication here is deliberately targeted towards the development of the society and, in doing so, facilitates meaningful discourses among members of the society.

There are several discussions around development communication, a concept that marries development and communication together. Different people have given different meanings to the words, development, communication and have influenced the global perspectives of what development communication is. For instance, some refer to development communication as a concept that is beyond behavioural and that it can be used to influence the development of a whole economy. Meanwhile, according to S. Riaz \& S. Pasha, "Development communication is mainly a transfer of information or knowledge leading to desired changes in behaviour. In that light, communication is merely instrumental, whereas, for others, development communication is itself a part of the development process."

In solidifying what makes up the concept of development communication, the Thusong Service Centre provided vital elements that makeup development communication. Firstly, it states that it is responsive. This means that it only includes information that is relevant for consumption. Also, information that is passed around is those that the exact needs of the public have subsequently influenced. Of this, it states, "People understand their own needs better, and through this approach, communication becomes a tool in the planning and development process, not a mechanism to persuade communities once unpalatable decisions have been made ('in their best interests!')".

Secondly, the development of communication is dependent on feedback. It adopts a two-way mechanism that allows everyone - the society, the media, and decision-makers - the chance to have dialogues about different information that is being transferred. Thirdly, development communication is about "innovation and creativity". The message that is being communicated should explicitly tell members of the society how it will benefit them, whether in the short-run or the long run. Concerning creativity, the Thusong Service Centre states, "Development Communication workers should, however, balance creativity with an understanding of what communities would be prepared to accept and where consideration has been given to the norms and prevailing values of that community."

The body also states that development communication should be validated independently, i.e. it is not what the government thinks and says. Here, there is an involvement of 'participatory mechanisms' such as NGOs and co. They would serve as a form of validator for communication for development. Development communication is also about sustainability and continuity. Whoever is giving the information must stay true to whatever it is they have said.

\section{Perspectives of Development Communication}

Since there are often different perspectives as to what development communication is, there are also different perspectives of the concept by different scholars and researchers and its workings in various climates across the globe. Various approaches have been taken in the study and practice of development communication. These shall be discussed in this paper in providing different perspectives on development communication.

\section{Approach-based Perspective of Development Communication}

In their paper, T. Nnaemeka, E. Uvieghara, and D. Uyo attempt to view the concept of development communication by considering different approaches. These approaches aimed to put the stages of development into motion. Of this, they note,

"Development Communication takes as its starting point both the 'Felt Needs' at the community or local level and the 'Action Needs' as identified by planners. The operational strategy for meeting these two 
sets of needs follows four stages of activities. 19 The first is identifying and analysing the innovations sought by the community and those that development agents want to introduce - to whom, when and with what material means. This is generally known as the diffusion stage in development communication. In the second stage, which is known as the social process stage, the thrust of activities is towards determining how existing social, cultural, psychological and organisational factors may facilitate or hinder the adoption of new practices among the groups of people concerned. In the third stage, efforts are geared towards identifying existing media and how they relate to them. Here, one looks at what combinations of communication channels exist and can be used in the communities: traditional and interpersonal channels and modern print and electronic media - for communication 'feed' both into and from the community or communities. Finally, after repeating these analyses for geographically or sectorally related projects, locally tailored communication programmes are drawn up and implemented in phases with the real action potential in the communities (taking into account available supplementary input from outside the community)."

With this in mind, some of the approaches are discussed in this paper below.

\section{Extension and Community Development Approach}

This method is the earliest adopted in facilitating societal development, although it is more rooted in rural communities development. It concerns itself with the use of information in impacting specific areas of society, including agriculture and health. However, communication has to be done physically, i.e. face-to-face. T. Nnaemeka, E. Uvieghara, and D. Uyo in Philosophy and Dimensions of National Communication Policy note that this approach makes several assumptions such as: "rural communities are interested in new ideas and practices to improve their living conditions. It also assumes that there are necessary and sufficient resources to support their endeavours, enabling them to apply available new information to useful development activities. It further assumes, as indicated in the Animation Rurale Programmes of Senegal, Togo, Ivory Coast, and Benin, that there is a crop of educated, intelligent and public-spirited leaders within the communities; who can motivate the masses to positive development directed endeavours."

India has also adopted this approach to development communication in the past. The country believed that many uneducated people in rural areas provided themselves as a "highly valuable development resource." However, this approach to development communication is not widely adopted like it used to be. Over time, countries have realised that there are drawbacks to its success. T. Nnaemeka, E. Uvieghara rightly support this, and D. Uyo, when they cite the example of the Comilla Project by Rahim, noting, "as the project expanded, it was noticed that the feedback mechanism was strained; the interpersonal channels were overloaded. The capacity of the system could not be increased within the inherent constraints of its structure. Hence, in subsequent Camilla-type projects in that country, the communication model used was that which linked mass media to inter-personal channels."

\section{Centralised Mass Media Approach}

This development communication approach focuses on centralising the framework for mass media and the path for the messages it produces. T. Nnaemeka et al. note that "it relies wholly on the mass media for its message flow and almost completely ignores the interpersonal system." Because there is a dependency on mass media to communicate information, they also note that the "coverage potential is substantial." This perspective of development communication is "based on the assumption that a 'good and relevant message' is capable of being accepted by the individual on his own, irrespective of the origin of the messages, and. that the best and hopeful way to attract and hold a mass audience is to offer open and spontaneous and continuous vicarious satisfaction as well as education." Many countries across the world approach development via communication through this perspective.

The centralised mass media approach draws its mechanism from the Development Media Theory, which according to T. Nnaemeka et al., "requires the mass media to join the government in the task of nation-building and development."

\section{Localised Mass Media Approach}

This perspective of development and communications also concerns itself with the media. It focuses on forming a discourse mechanism with public members in the form of media channels. Here, there is an identification of 
the significant issues facing society. According to T. Nnaemeka et al., these problems can be identified through "personal calls, meetings and discussions by media personnel who are required to enter into the people's sociocultural context. Because of the need for specificity in message content, the localised method calls for the establishment of local media - local radio, rural press, television production studios and viewing centres." A framework like this allows people in rural areas to participate in planning and executing messages for development purposes.

\section{Participatory Model of Development Communication}

Much like some of the approaches, this model of development communication also encourages an exchange of information and dialogue between people who know and those who do not. S. Riaz and S. Pasha note, citing Morris (2003), "In the participatory model of development communication, the transmission of information is not a vertical process of information flow from the knowledgeable to the less knowledgeable; instead, it is a horizontal process of information exchange and interaction Power in Development Communication (Morris, 2003)". The idea in this perspective of development communication is to strengthen members of the society so that they can have positive influences on development-oriented decisions.

\section{The Integrated Approach}

There is a merging of interpersonal communication and the mass media in the integrated approach of development communication. While interpersonal communication considers other perspectives like the extension and community development approach, the mass media adopts centralised mass media approaches and a localised mass media approach. These are then connected with the different means of communication around. Concerning the differing traditional modes of communication in different climates, T. Nnaemeka et al. note, "The structure of communication in any society is largely determined by the growth and development of technology and by economic and cultural institutions. To the extent that societies differ in their patterns of economic and socio-cultural heritage, their communication patterns also are likely to differ." The integrated approach aims to give information to both the traditional and interpersonal communication channels so that various discussions are generated and ensure that everyone understands their duties in achieving the development objectives.

\section{Status quo on Development Communication in Nigeria}

Most African nations, including Nigeria, are still battling to accomplish the ideal development level, so they have been labelled as Third World or Developing Countries by the West. According to Thirlwall (2003), some of the issues common in the so-called Developing Countries include Low level of capital growth, fast population growth, exports comprising primarily essential commodities, joblessness, poverty, absence of basic welfare needs, and poor industrialisation and development. Invalidating the above attestation, Diso cited in Harande (2010), asserts the structural and infrastructural issues, corruption, unstable political and economic policies, increasing insecurity, and erratic power supply are the central point discrediting the course of development in underdeveloped nations. Different communication policies have been set up to propel the course of development and the accomplishment of the millennium development goals in Nigeria. These policies also help in the stipulation of the press duties and checking their country's activities.

There must be communication focused on giving the majority fundamental data that will empower them. For citizens to be interested in development, it must be commendable and sustainable development inside a country. Development is a consistent process. Accordingly, whatever is set up today ought not to hamper the continuous process of development, thus sustainable development. Because of communication's value-based and transactional nature, there is sharing of information via participation and cooperation.

To encourage successful communication for national development and growth and delineate activity limits, the Nigerian federal government set up the communication policy. The National Communication Policy spelt out the obligations of the different media of communication regarding programming and news coverage, so it lines up with the national interest and development strategies.

In the print media, where we have the newspaper, and the National Communication Policy stipulates that the print medium must be utilised as a vehicle for a national mobilisation to support the policies and programmes designed and intended for the improvement of the way of life of Nigerians, and raising the level of their 
awareness. The print media's job includes supporting and promoting the positive parts of our national values, image, corporate unity, stability, and strength.

Likely to guarantee a better outcome, the policy also took note of the significance of our conventional structures and the need to instil them in fulfilling the individual goals and the accomplishment of national development. For this, the national policy supported the direct public and private interest and investment in community-based print media in the rural zones to meet the people's needs for information.

To further the efforts towards accomplishing national development goals with a significant focus on the local community that produce the country's most considerable populace, the policy demands that federal and state governments allow a sensible amount of their rural development funds to establish community-based media of mass communication.

Taking a good look at all the mandates and regulations in principle, there is a likelihood that one may pass judgment on it to be close to flawless if not "superbly immaculate" in accomplishing the national desires and objectives of development in Nigeria and practically speaking. Anyway, the principles are not being fulfilled as they ought to in some areas and have even failed woefully in several regions. Hence, it is crucial to mention some of the issues weighing against the suitable utilisation of the communication policy to accomplish effective national development and individual goals. Since 1987, when the policy should have begun taking roots, the Nigerian state has been facing specific issues militating against the possible use and execution of the principles and regulations contained in the national communication policy for national growth and development. Some of the problems that have been observed include poverty, corruption, unstable power supply, inadequate political frameworks, spatial disparity, journalist practice against principles, and low grass root interest and participation.

Several issues abound in Nigeria's national communication policy and its roles in different media towards national development. The resulting problems stem from executing these roles, which are to be played by the government, journalists and the masses. The government typically attempts to manipulate the media to further their political interest. On the other hand, the journalists posit that they won't be bribed or silenced and will carry out their responsibility without any form of fear or favour to any individual, group or interest. While the masses stay passive in their participation in information sharing and the execution of development strategies, genuine national development will only be a mere dream.

Following the national communication policy in Nigeria, there is provision for utilising traditional media, which is mandated to be utilised alongside the existing media. The conventional media's role can't be undermined in the strengthening process for national development. It is being relied upon in most rural community as a credible method for sharing information. Innate in the conventional media are the advancement and promotion of cultural heritage and legacy and objects, particularly those with communicative value and the utilisation of the local languages, which relegates to the background the issues regarding illiteracy and language barrier during communication. Owing to the nature of this media and its instilled in the general population's way of life and culture, local engagement and participation must encourage viability in utilising the traditional medium towards the accomplishment of national development.

So far, it is clear that there is still a lot of work in Nigeria on development communication. Many political and socio-economic issues need to be addressed to develop communication and ensure and attain national development.

\section{Theoretical Framework The Paradigm of Modernisation}

This Paradigm of modernisation is considered a significant element of development communication and forms its growth as a concept from the 1950s to the 1970s. Here, the idea is based on the liberal political theory and, as a result, rooted in the "grand project of the Enlightenment" (Ebigbagha, 2016), a project of reasoning, objectivity, rationality, and other philosophical principles of Western science. Theories of modernisation defined a modern nation as one that can be likened to the West's nations in every sphere of society. These included parameters like "political and economic behaviour, institutions, attitudes toward technology and science, and cultural mores." Significant credence was given to economic growth, which was benchmarked by a nation's gross national product and many more.

According to Ebigbagha (2016), wealth and development occur in a week and undeveloped society or receiver when ideas are disseminated into it from rich and developed society or source." This gives credence to the singular (one-way) type of communication. The more rounded and privileged provider of information offers 
information to the less privileged, which he thinks is just enough for the less privileged. This can be sourced from the social evolutionary theory. On a grander scale, these theories of modernisation adopted other theories in their propounding. Of this, Moody states elaborately as thus:

"At the macro level, theories applied Darwin's ideas to the process of modernisation of human societies. The theories of social evolution influenced and gave rise to important concepts in the sociology of development, such as the various bipolar theories of modernisation. In those theories, the universal stages in the earlier theories of social evolution were reduced to the micro-level, theories on individual psychological attributes stressed that attitudinal and value changes among individuals were prerequisites to creating modern society."

\section{The Paradigm of Dependency}

Dependency concerns itself with the communication of ideas from one developed society to an undeveloped society. According to this Paradigm, this is a prerequisite for development. The Paradigm also holds a dependency between the source and the receiver in the development process, and the receivers' socio-political structure must be considered. It adopts the transmissive/diffusion models of communication, citing examples that include the following: Rogers Innovative Diffusion Model, 1973; Ball-Rokeach and Defleur's Dependency Model of Mass Communication Effects, 1976 and Freires' Consciousness Model, 1970 (McQuail and Windahl, 1986; Servaes and Malikhao, 1994; and Garland, 2005a, Vineet, 2011).

These adopted models of communication helped fix focus on the usage of stimulus to facilitate individuals' development. Rogers (1973) explains that “...to facilitate the decision to adopt and confirm adoption of development messages, it is necessary to know the receiver and the social system variables.". This informed respondents for this study being citizens and lived in the country within the research window, $2008-2018$. However, to incorporate the communication nexus with development, the following theory became necessary, The Paradigm of Another Development/Multiplicity.

\section{The Paradigm of Another Development/Multiplicity}

This concept posits that "development is seen as a product of collaboration and participation of all stakeholders, and communication is seen as an essential tool for participation." This Paradigm, when compared to the first two, is more rounded. Since it believes that any actual development is generated from within (a society), it considers society members' fundamental problems. It encourages them to be a part of the solution. The Paradigm adopts participatory communication models. Here, the communication follows a two-way path such that everyone is involved.

Garland (2005) further discusses Berrigan's Methodology of Community Media, which is an example of a typical two-way communication model, explains this model further, emphasising interactivity and eight steps:

"The first step is identifying the felt needs utilising direct interaction with the receivers. The second is Concretization, which examines the needs identified by the receivers in the light of local conditions. The third is the Selection of priority problems by the receivers. The fourth step is to formulate a durable methodology for seeking solutions to priority problems of felt needs. The fifth step is the Identification of the Amount of Information Required and Access to this information. The sixth is Action Execution by thorough participation of the receivers of the project that they have designed. The seventh step is the Expansion towards the outside to make known the receivers' point of view to other receivers or the authorities. And the eight-step is the Liaison with the communication system to make known the action of the receivers to others that could benefit from the experience of the receivers, who carry out actions to execute identified needs."

This theory encourages collaborations within society. When people can realise issues facing society together, they should inform decisions that can spur society's development. And this can be facilitated through communication, sharing information from one end to the other of the equilibrium. 


\section{Methodology}

Data for this descriptive research study was collected via a semi-structured online survey instrument. Respondents were Nigerian citizens resident in the country, above 18 years (legal age), and have witnessed the country's developments and communication between 2008-2018. Respondents were targeted using snowball sampling. Findings were analysed via interpretive analysis, cross-tabulating, filtering results using visualisations of data.

\section{Findings}

From the data gotten from all the 130 respondents, we had 62 female respondents amounting to $47.7 \%$ of the sample population. The remaining 68 respondents were of the male gender, amounting to $52.3 \%$ of the sample population. The result of the analysis is shown in figure1.

\section{Gender}

130 responses

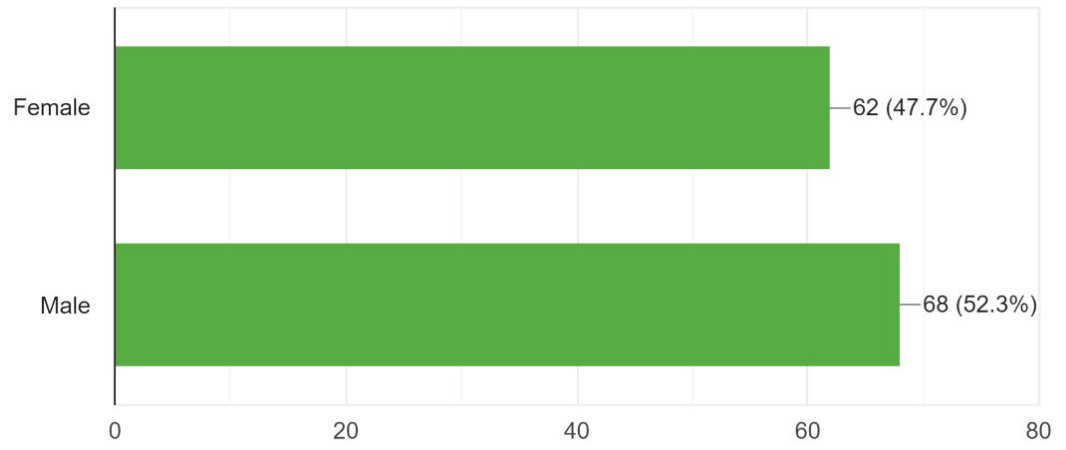

Figure 1: Gender of respondents. $\quad$ Source: Field Survey, 2019.

Age Range

130 responses

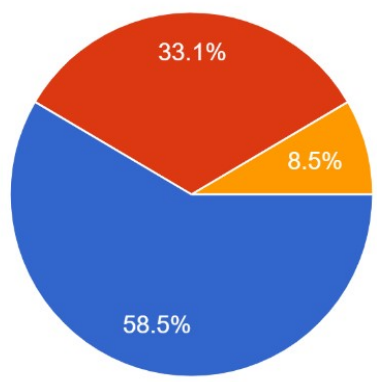

$18-34$

$35-50$

$51-69$

$70-87$

Figure 2: Age distribution of respondents.

Source: Field Survey, 2019 
4. Are you a Nigerian?

130 responses

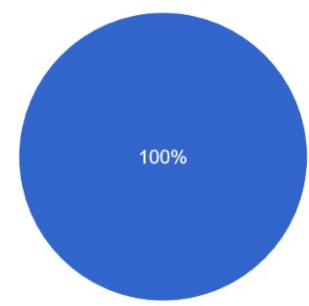

Figure 3: Citizenship of respondents.
Source: Field Survey, 2019.

We also looked at the respondents' age distribution, in which $58.5 \%$ are within the age range of $18-34$, while $33.1 \%$ and $8.5 \%$ of the respondents fall in the age range $35-50$ and $51-69$ years, respectively. For credibility and reliability, only adults needed to participate in the online survey, hence the distribution. The higher number of respondent respondents being in the 18-34 years bracket shows adaptability to technology. The data also indicate that the active working population is abreast of community developments and online and offline communication. This further gives credence to the information they provide.

It was essential to state that all our respondents are Nigerians and live here, some of whom have different professions, like lawyers, accountants, etc. This spread in respondents professional affiliation provided a broad perspective and guaranteed informed responses to strengthen data quality.

Now, part of the questions we asked the respondents as if they've noticed any Development(s) in Nigeria (between 2008 and 2018), and interestingly, 66.2\% of the respondents said that they have, 10.8\% said they haven't, and then $24.6 \%$ were not sure.

\section{Have you noticed any Development(s) in Nigeria (between 2008 and 2018)?}

130 responses

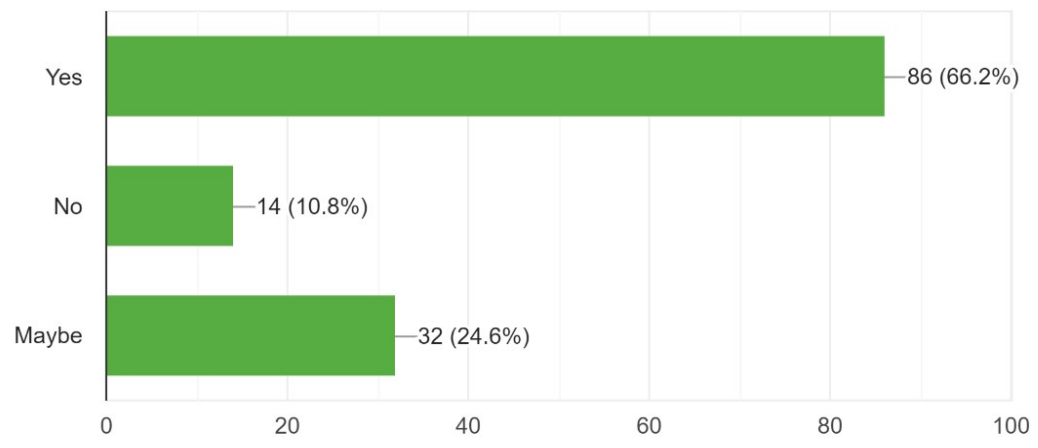

Figure 4: Notice of developments in Nigeria between 2008-2018.

Source: Field Survey, 2019.

However, most of them shared similar opinions on the various medium in which the government makes known to Nigerians information about the new developments that have been completed. Most of them listing different media options like TV, Radio and newspapers. All of which form media channels for broadcasting.

Furthermore, the respondents were asked about the different developments noticed between 2008 and 2018. Ten close-ended options of national development were used to facilitate their responses. These were Entrepreneurial Empowerment, Public Awareness on Government Activities, Technological Development, Favourable Policies, Foreign Investments, Roads, Increase in Export, Economic Growth, Human Capita and Infrastructure. 


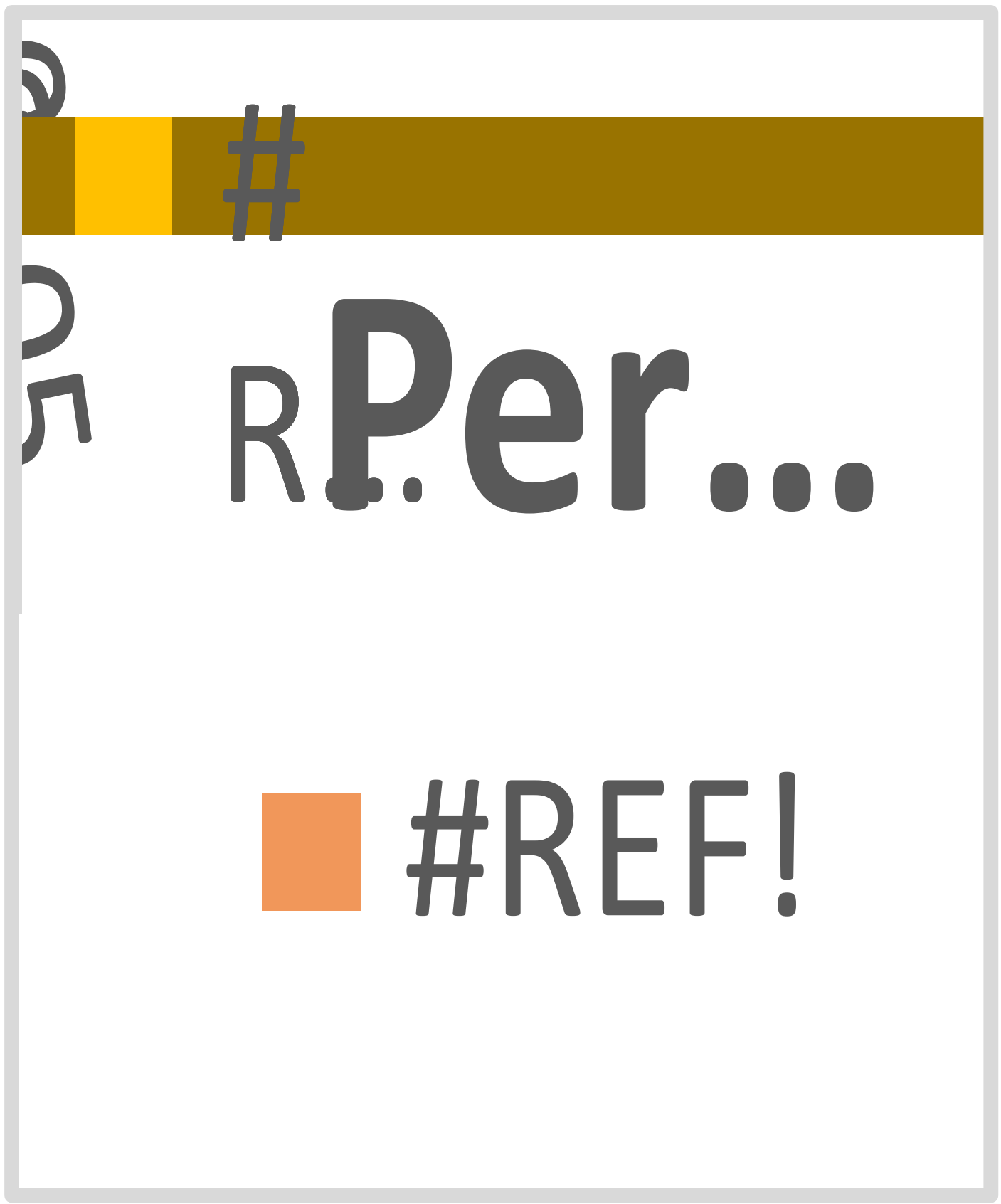

Figure 5: Likert Scale ranking type \& frequency of development between 2008- 2018. Source: Field Survey, 2019. 
Beyond the chart presented, statistical analysis using excel indicated the overall occurring level of development, as shown below:

Overall Scale $\quad$ Level of Development from 2008 -2018

\begin{tabular}{l|l|}
\hline Never & $19.53 \%$ \\
\hline Almost Never & $21.13 \%$ \\
\hline Rarely & $24.96 \%$ \\
\hline Sometimes & $20.83 \%$ \\
\hline Often & $7.73 \%$ \\
\hline Very Often & $4.52 \%$ \\
\hline Always & $1.30 \%$ \\
\cline { 2 - 2 }
\end{tabular}

A cross-tabulation of the data above reveals over $65.6 \%$ of the population saying that developments never or rarely occur across the nation compared to government responsibilities and citizen expectation-also, only about $34.4 \%$ rate of observable development occurrence.

We continued by asking the respondents how they found out about society's development within the timeframe. And we observed that unsurprisingly, most of them found out through social media, television and radio; $72.3 \%$ of the respondents stated social media as their primary source of information, with $60.8 \%, 37.7 \%$ and $31.5 \%$ of the sample population sating Television, Newspapers and Radio respectively. A detailed analysis is shown in figure 6 below:

8. How did you find out about the development(s) in society between 2008 and $2018 ?$

130 responses

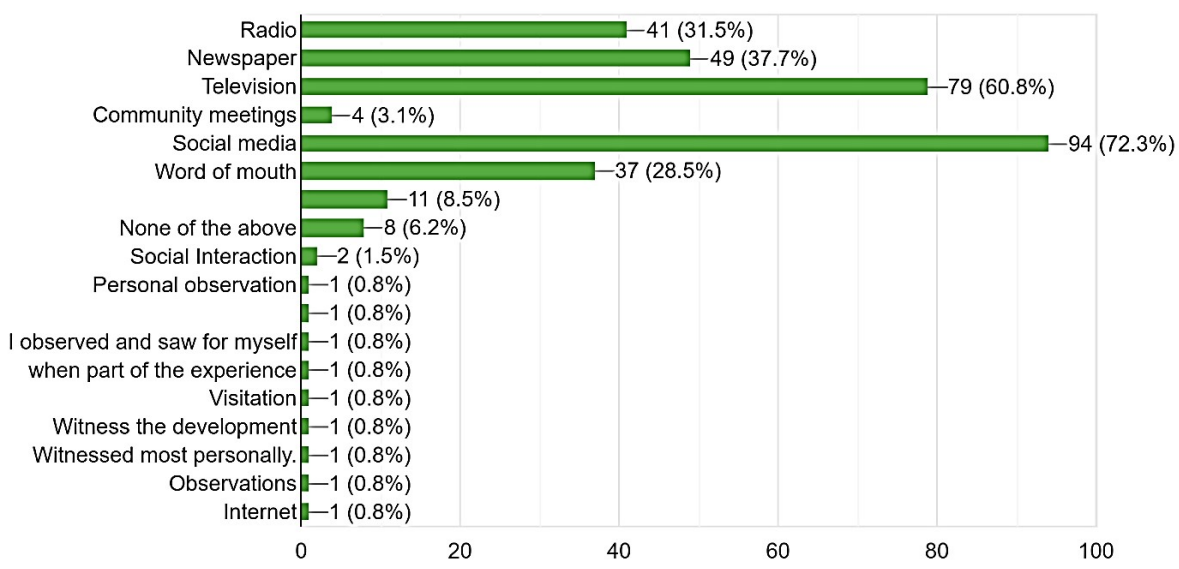

Figure 6: Respondent's source of Development news. $\quad$ Source: Field Survey, 2019.

Sequel to the previous question (Figure 6) and as a way to identify correlation in the response, we asked the respondents how the (Federal/State/Local) government communicate these developments to the public. Their response (Figure 7) showed an interesting outcome. In this case, 67.7\% stated Television, while 53.1\%, 48.5\% 
and $43.1 \%$ stated Newspaper, Radio and Social Media, respectively. While similar channels were used, the distribution of engagement with these channels differed. The government chose more traditional channels for communication compared to citizen's indicated source of development communication. Again, a summary of this is shown in figure 7 below:

9. How did the (Federal/State/Local) government communicate these developments to the public? 130 responses

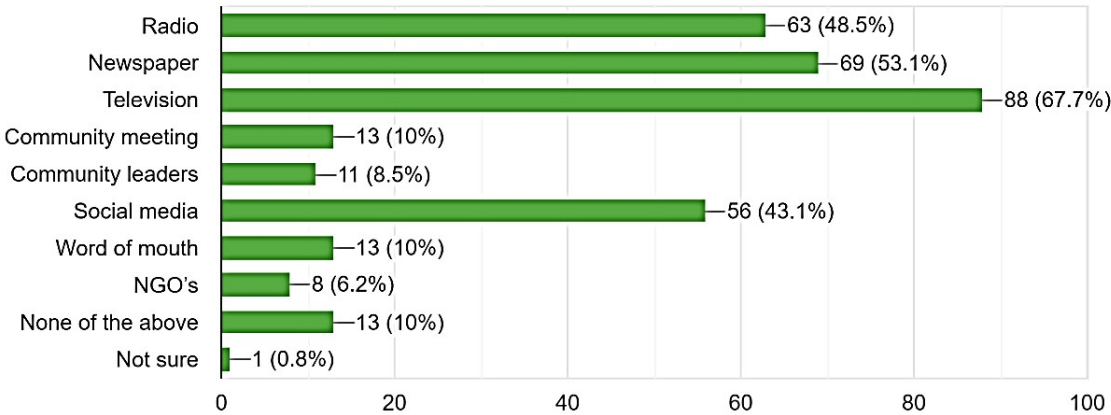

Figure 7: Development communication channels between 2008-2018.

Source: Field Survey, 2019.

Finally, to consolidate what has been asked (A way of "Crossing the t's and dotting the i's"), we asked the respondents how they would like to get information about development in Nigeria unsurprisingly, $73.8 \%$ selected Social Media. In comparison, $61.5 \%$ opted for Television amongst others. The detailed analysis is shown in the figure below.

10. How do you prefer getting information about development in Nigeria?

130 responses

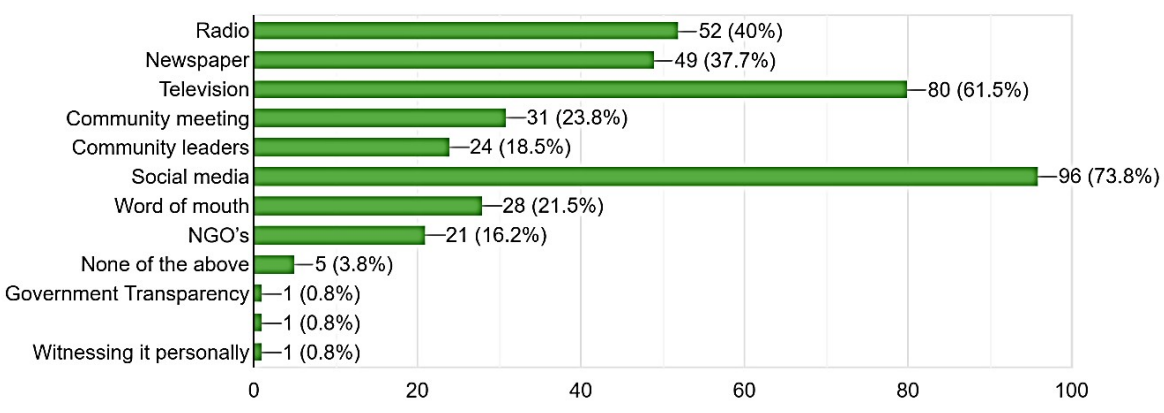

Figure 8: Citizen Preference of Channels for Development Communication.

Source: Field Survey, 2019. 


\section{Discussion}

\section{New Media As A Platform For Social Sphere To Achieve National \& Development Communication In Nigeria}

The emergence of the new media made the public sphere much more active than ever before. This meets Jurgen Habermas's idea, who regards the public sphere as a virtual or imaginary community. Social media, a great product of the new media, has (and continues) to provide an elaborate platform among people from different walks of life. In The Role of Social Media in Development, Rosie Parkyn acknowledges that social media is "facilitating discussion, inspiring action and enabling engagement", stating that social media has an advantage over mainstream media in that it gives voice to everyone "on their terms." Parklyn's article placed the Arab uprisings in perspective and how social media contributed to the outcome. She states that social media significantly contributed to bringing about uprisings. It provided means of transforming individualised, localised, and community-specific dissent into the collective consciousness and shared opportunity in action taking. In evidence, she quotes an Egyptian protester that said, "We use Facebook to schedule the protests, Twitter to coordinate and YouTube to tell the world."

Current social media tools are inclusive and allow for continued participation in the public sphere. And this can have a positive effect on the Nigerian ecosystem. For one, social media allows for increased social interaction between citizens of different ethnic and religious perspective. Social failures occur in societies due to members failing to interact with each other - the lack of social interactions. Because it is virtual interactions via social media, help to remove some sort of discrimination from conversations. For instance, people with physical disabilities can easily have meaningful conversations about critical issues with other members of society without the other person necessarily knowing the status of the disabled person.

Social media can also contribute to education in the country. Over time, social media has often been seen as a stumbling block to the academics of youths. But it has proved to be a contributor to students' education. These days, knowledge can be easily shared in bytes among people. WhatsApp and Facebook groups can now be created to discuss relevant topics, where members can share ideas and educate themselves in the absence of a physical classroom. Anyone can wear the "student" and "teacher" tag.

Consequently, social media has served as a vessel for inspiration. Thought leaders abound on different channels, including platforms like Twitter and Facebook. They use these channels to project their thinking on some issues, inviting public members to learn, counter, and share their opinions. And this is indeed one way a society can develop and begin to remove ignorance, establishing a community of people who know what is good for them as individuals and society. Youths can have conversations with the old on the platform without any age discrimination.

The new media is influencing Nigerian politics as well. Hence, it is no surprise that the Presidency acknowledges this and appointed a Head of Digital Communications to oversee this aspect of the public sphere. As a result, the individual, currently Tolu Ogunlesi, is actively involved in communicating with public members, joining in the public discourse. Now, development can be sourced from this area if he can monitor the general opinions of the public on some political issues and communicate them to the Presidency, ensuring that these issues are then addressed.

New media (social media in this case) also breeds an understanding of the different cultures in the country. There has always been a prejudice that could be easily perpetrated about different beliefs and cultures simply because there isn't an understanding of its people. With the advent of social media tools like web blogs, Facebook, and Twitter, members of any culture can take it upon themselves to provide adequate information on some of the assumptions about their beliefs.

Like in many other countries, social media can also help the public choose its leaders collectively. Some organisations even take it upon themselves to facilitate public discourses during election periods. Through new media technologies, Adebola Williams, a Nigerian media entrepreneur, has helped three presidents win elections in Africa. This will help national development if these persons are the clear choices of the public. Leaders who the public have collectively judged in the public sphere and decided that this is the right individual to handle the country's affairs.

National development is faster and easier when every member of the society plays a role in its achievement. This would have been nearly impossible in the past, but with the advent of the new media, everyone could actively use these new technologies to participate in the public sphere. They don't have to be physically present to contribute to the development of the nation. 


\section{Conclusion}

The new media, public sphere, and national development form an interrelated entity whose collective successes are somehow dependent on each one's success. The new media is here to stay. The Nigerian ecosystem must adopt it and continually use it to participate in the public sphere and ultimately affect its positive changes.

Earlier, we considered the Paradigm of Another Development/Multiplicity, positing that "development is seen as a product of collaboration and participation of all stakeholders, and communication is seen as an essential tool for participation." The field survey indicated a disconnect in development communication and, by extension, collaboration with citizens. Communication is fundamental in the process of development and development communication. Thus findings on preferred channels for development communication is crucial.

Inclusion is also vital as public discourses must be inclusive of all and sundry, including the elite and minority and everyone else. Nigeria is about 180 million people, with over half of this population being active Internet users. This means that the public sphere has potential for expansive movements, mobilisation and thoroughness in discourse if guided.

There are several ways by which the impact of development communication can be measured. S. Riaz provides some ways and S. Pasha in their paper Development Communication in a Global Perspective. "The most popular measures to determine the impact of development communication is knowledge gain, frequency of media use, and behaviour change - all of them individual-level measures."

Development communication is a pivotal contributor to the growth of a society and the well-being of its people. Several economies now adopt the concept of taking their economy to the next level by deploying mass media to build a more conducive environment for modernisation and industrialisation. They allow members of the society to be direct or indirect drivers of the development of the society. United Nations (UN) explains its impact on human development, suggesting that "democracy, decentralisation and the market economy empower individuals and communities to control their destinies."

\section{References}

Ball-Rockeach, S. \& Defleur, M. L. (1976). A dependency model of mass media effects. Communication Research, 3:3-21.

Baran, S. J. (2009). Introduction to mass communication: Media literacy and culture. New York: McGraw-Hill Companies, Inc.

Chandler, D. (1994). The transmission model of communication. UWA, http://www.google.ie Last Modified: 01/22/2006 17:10:12 Retrieved on 7/5/2006.

Ebigbagha, Z. S. (2016). Major development communication paradigms and practices: Implications for graphic communication. African Research Review, 10(3), 317. https://doi.org/10.4314/afrrev.v10i3.21

Etana, A. (n.d.). The Characteristics of Development Paradigms: Modernisation, Dependency, and Multiplicity. Development Paradigms/Discourse. Retrieved April 12, 2021, from https://www.academia.edu/7815006/The_Characteristics_of_Development_Paradigms_Modernization_ Dependency_and_Multiplicity

Ebigbagha, S. Z. (2016). Graphic encoding choices in development communication: identifying the several loops of graphic encoder/media team collaboration. Omniscriptum Gmbh, Germany: Lap Lambert Academic Publishers.

Ejembi, E. A. (1989). Graphic Communication in Development Programmes: Models for Communicators. An Unpublished PhD. Thesis, Department of Typography and Graphic Communication, England: University of Reading.

Fraser, C. \& Villet, J. (2005). The context of communication for sustainable development. In Communication and Sustainable Development. Communication for Development Roundtable Report, United Nations.

Garland, D. (2005). Capital punishment and American culture. Punishment \& Society, 7(4), 347-376. https://doi.org/10.1177/1462474505057097

Harande, Y.I (2010). Library Philosophy and Practice. http:/www.webpages.uidaho.edu/ mbolin/har 
Ilu, I. Y., \& Olawale, F. (2014). The Cogency of Melkote's 'Another Development' for Development Communication in the Third World. In Procedia - Social and Behavioral Sciences (Vol. 155, pp. 242247). https://doi.org/10.1016/j.sbspro.2014.10.286

McQuail, D. \& Windahl, S. (1986). Communication models for the study of mass communication. London, England: Longman

Lasswell, H. D. (1948). The structure and function of communication in society. In Bryson (ed.) The communication of ideas. New York: Harper and Brothers.

Servaes, J. \& Malikhao, P. (1994). Concepts: The Theoretical Underpinnings of the Approaches to Development Communication. In Mayo, J. \& Servaes, J. (ed). Approaches to development communication. An orientation and resource kit. UNFPA, UNESCO

Thirlwall, A.P (2003). Growth and Development with Special Reference to Developing Economy. New York, Palgrave Macmillan. 